\title{
DIGITAL ARCHITECTURE MANIFESTING AN ACCURATE VIRTUAL BUILT ENVIRONMENT
}

\author{
Suryakala Nannapaneni ${ }^{1}$, Ravindra Patnayaka ${ }^{2}$ \\ ${ }^{1}$ Assistant Professor, GITAM School of Architecture, GITAM University, Andhra Pradesh, India \\ ${ }^{2}$ Assistant Professor, GITAM School of Architecture, GITAM University, Andhra Pradesh, India
}

\begin{abstract}
"God lives in details" - it be the aspect of an intricate construction detail or an attribute assigned to a 3D model, all it matters is bringing out the most accurate interpretation of architect's thought process. The best medium for communicating the virtually manifested ideas from concepts to the analytical research can be "a visual". Providing a visual in the form of a sketch, drawing, perspective or an analytical report, used to depend only on the ability of manual presentation skills of the architect or designer. The client's provocation in knowing the possible outcome as realistic as possible validates the anticipations former to execution igniting and intensifying the challenge of producing more accurate presentable visuals by an architect. Computer aided design tools and certain software facilitates beautified, presentable, streamlined, accurate, professional interpretation of architects ideas, manifested thought processes using many tools such as a drawing, logical or analytical simulators, etc. that contribute in creating the virtual reality at its most possible accuracy levels. Software is a communicator of the resource capital of design, i.e. "Architect's idea", and facilitates in visual perception of all the other stakeholders. The bits and bytes of various idea sparks by an architect can be programmed on a logical platform with various software languages to produce a "visual" on the silicon screen. Architectural design process is both common and unique for a student, academician, research anticipator or a professional, ranging from concept to the final presentation outcome. This paper gives a consolidated account of various softwares that can ease out the manifestations of thoughts on a digital platform for producing more accurate and presentable interpretations.
\end{abstract}

Key Words: Architectural design, virtual reality, softwares, visuals, drawings, digital architecture, presentations, sketches.

\section{INTRODUCTION}

Architectural interpretation transformed dramatically over the past few decades, largely due to the advent of internet, personal computer and commencement of diverse software in this discipline. Challenges that the practicing Architects, educators, academicians and professionals faced includes dilution of the traditional sense of presentation, i.e. the sketch; a manual and conceptual system of drawing, was vanishing and with it in many cases the intelligence and visual literacy that is a part of the making has drawn to the end of architecture. Architects found themselves in ambiguous space where there was a tremendous shift in the means and methods of presentation. Architects who have adapted to these ongoing changes have succeeded in convincing their clients in an efficient manner.

Architects used to deal with lines and spaces, printed their combinations on paper which was used as a common language of their design communication through plans, sections, elevations, 3d-views, perspectives, details, etc.[1] In the recent decades, the drawing practice has begun to heal tools and modes of thinking, interpretation and novel processes have emerged in architectural design that feats the computer as a design instrument. This has yielded a varied set of digital accomplishments and a new case of architectural knowledge base. Architectural software such as
Revit, Rhino, 3dsMax, etc., have led Architectural drawing practice to shift radically in different modes. The line is seeded ground to surface in volume and form was considered as a $3 \mathrm{~d}$-object with construction of a reality in space.

Despite this transition into the digital world and the increasing prevalence of digital production, drawing is still defined as a traditional method of learning and conventional model of practice in architecture schools in order to strengthen the basic ideology and creative mindsets of students. Upon reaching the sophomore phase, students were introduced to the electronic world of visualization. However, until today, a hypothetical framework is missing that would allow for a universal pedagogical program for educating digital design in architecture. A theoretical foundation based on the concept of estimated occasions listing out varied software utilized for specific purposes at every stage of an architectural project is necessary that provides an intangible and conventional view on digital presentation that permits segregation of contemporary digital design methods and an understanding of their coherent relationship. Conjecturally, it opens a route for the study of the concepts that alleviates transfer of ideas from various technological domains into architecture. 


\section{WHAT IS DIGITAL ARCHITECTURE?}

Digital Architecture is a discipline that employs digital media i.e. machine-readable electronic media such as imagery, computer modeling, simulation, databases, programming, e-books, etc. in the process of conceptual to the design development. [2] It helps in developing drawings at different phases of the project, such as virtual forms, realistic structures and detailed working drawings. A range of complex conceptual models of design proposals are created at ease using several series of computer algorithms and the rendered built structures may or may not involve actual material applications such as wood, glass, brick, stone, etc. based on the designs but banks on a set of permutations and combinations of numbers stored in electromagnetic format. This alleviation in generating nonstandard forms using various logical derivations in digital softwares resulted in a new revolution in architecture, for instance, works of renowned architects such as Zaha Hadid, Santiago Calatrava, Daniel Libeskind, etc.

\section{ORIGIN OF 'DIGITAL ARCHITECTURE'}

Technological innovations in different disciplines resulted in an artistic approach to architecture that led to the beginning of Digital architecture. Globally accepted means of digital softwares were created that helped in taking over international projects by domestic architectural firms. [3] However, the conventional means of drafting on a drawing table forms the basic learning criteria in architecture schools, few training institutes and offices. Most of the architectural firms take advantage of the array of possibilities these digital media offers in creative and quick outputs that enables careful analysis of both physical and functional aspects of a structure prior to execution. [4]

\section{PRESENT SCENARIO}

The advancing use of World Wide Web has thoroughly reciprocated the way we approach in designing a given space. Digital architecture has facilitated us to perceive and understand designs using the virtual demonstration of spaces with innovation practices such as Building Information Modeling, structural stability, on-site construction feasibility, etc.[5] Several parametrically designed models operated by different spreadsheets, complex numerical calculations, combinations, material applications, performances and scripts are changing the way the built structures are designed and constructed.[6] Such Smart Building technological implications has changed our approach of exploiting the nature and resulted in designing Green buildings, Zero-energy structures, etc., a sustainable way of living to preserve the available natural resources for future generations with minimum damage to the site and its surroundings.

\section{FURTHER DEVELOPMENT}

"The future is above all a question of design" - Vilem Flusser

Digital Architecture has significant implications at multiple phases of design processes. Design fabrication, mass modeling, prototyping, parametric designing, computer based iterations, etc. have accelerated the embryonic growth of versatile concepts based on inspirations from nature and further ameliorates our perception of spaces. Architectural agencies deal with time-based projects and in order to meet the specified deadlines they tend to choose the fastest and cheapest means of processes.[7] Digital technology in combination with a creative mindset enables innovative designs within no time and simulation softwares facilitate realistic sustainable and responsive design approach virtually prior to construction. However, few exemplary designs based on fantasies were generated with a complete digital state of mind restricting the involvement of the human designer and be considered as a more robotic end product.

\section{SOFTWARE FOR SPECIFIC PURPOSE}

It remains one of the biggest challenges for architectural students to decide upon the type of software one needs to learn during under-graduation in order to attune themselves in this competitive world. [8] The entire design process can be divided into different stages and the diverse digital software library helps in easing up the development of final output.

\subsection{Conceptual Development}

A concept may be defined as an abstract idea developed during the design process, i.e. from genesis through transformation of various thoughts interpreting the context. Architecturally, a concept may be implied as the main idea or a series of ideas, a systematic approach, a directing principle or a design objective. An architect should grapple with the actual form, function, mass, scale, solids, voids and the aesthetic appeal of structure with respect to its neighboring context. [9] Concept focuses on a central idea among the multiple alternatives evolved during the thought process, understanding the brief precisely and helps in a more feasible design at the early appraisal phase of the project. Architect will present a series of conceptual sketches, thoughts, ideas, illustrations, explorations, plans, elevations, sections, views, perspectives, models, etc. in order to interact with the client effectively. Further discussions with the client may result in several adjustments, modifications and upon the clients satisfactory event of approval, the final set of refined drawings are prepared and sent over to professional consultants, contractors, engineers, supervisors, etc. for further developments. Architectural software development has made this task easy with the varying interpretation modes of presentation templates, elements in all the categories such as anthropometry, landscape, plumbing, vehicles, etc.

Recommended softwares: Sketchup, Revit (mass modeling), Microstation, ArchiCAD, ConceptDrawPro, SmartDraw, 3DsMax, Maya, Rhino, Grasshopper, SolidBuilder, IStruct, EasyBluePrint, BridgeDesigner, etc. 


\subsection{Drafting}

Drafting is the basic language of Architects to communicate their ideas or designs to their clients. It involves several compositions of elements framed using various symbols, perspectives, notation criteria, measured units, visual styles, page or sheet layouts, etc. A completed drawing is unambiguous, self-explanatory and is relatively easy to understand by similar professionals. [10] A set of standards and specifications were followed globally as a conventional means of drafting that will help in dealing with international projects. Drafting requires a thorough understanding of spatial comprehension, geometry with precision, accuracy and careful attention to all details. It can be done either manually- using T-Square, parallel bars, setsquares, triangles, French curves, Spline, etc., or by using computer aided softwares- such as AutoCAD, Microstation, etc. The Computer aided drafting is done on an electronic drawing board which is accurate and facilitates several revisions for the same set of drawings unlike manual drafting where a new drawing has to be generated starting from scratch. The drawings can be made for several disciplines such as architectural, electrical, plumbing, sanitary, etc. in plans, elevations, sections, views, perspectives, etc. to interpret and explain the complete design ideology.

Recommended softwares: AutoCAD, Grabert Custom CAD, GTXRaster CAD Series, ProgeCAD, STAAD, CMS IntelliCAD Software, SoftPlan, ENvisioneer, Arris Architect Studio, CADopia, Draftit, DesignMaster Electrical, ZWCAD, Punch Software, DraftSight, LibreCAD, NanoCAD, TurboCAD LTE, BricsCAD, iCADMac, DataCAD, ProArchitect, ProgeCAD Architecture, TurboCAD Pro Platinum, Chief Architect, Revit, etc.

\subsection{Presentations Drawings}

Presentation drawings are a set of drawings that are created to articulate and communicate the basic design concepts and virtually manifested ideas by the design team to their clients. They help in explaining a design proposal with the forthcoming benefits or opportunities using aesthetically appealing realistic 2-dimensional or 3-dimensional drawings. [11] They play a very important role in designs that involve stakeholder participation where the proposed structure is visually perceived by clients, government and other private agencies and any revisions were made as per the feedback received so as to enable comfortable living for the inhabitants. The presentation drawings include intricately rendered site plans, floor plans, elevations, crosssectional views, views, etc. [12] The quality of the end product of presentation drawings depend on synchronizing the client needs, the drawing requirements, the Architect's creativity and the mode of presentation; either manual drawings or the softwares used to ease up the process.

Recommended softwares: Photoshop, Illustrator, Corel Draw, Edificius, CorelCAD, Domus-CAD, Vector Engineer, Painter, QuarkXPress, Muse, Cinema4D, Plo View, Dwg Viewer, Vertex BD Architectural, etc.

\subsection{Working Drawings or Details}

They are the set of drawings that are passed on to the construction team to enable the project execution. They contribute in attaining statutory approvals, construction proceedings, supervision of on-site execution, procurement of components, on-site instructions, etc. Working drawings include all scaled drawings- structural, civil, mechanical, electrical, architectural showing detailed plans, elevations, sections with necessary dimensions, symbols, specifications, and graphical information to help the project team proceed further. Any revisions and on-site adjustments which are acceptable with quality and engineering under expert supervision provided the updated set of working drawings reflecting all the changes to the works during the construction were clearly documented.

Recommended softwares: AutoCAD, AutoCAD LT, AutoCAD Mechanical, Revit, Grabert Custom CAD, AutoCAD Civil 3D, STAAD, Inventor (ED), BuilditLive, Arch Administrator, etc.

\subsection{Rendering}

Rendering is a process of creating an image from 2dimensional or 3-dimensional virtual model by manually or by means of computer generated programs. The conventional rendering techniques involved in the development of drawings taught in the under-graduation provides us with a better understanding of various color theories, textures, tints, shades, shadows, light, dark, bump, reflections, refraction, diffraction, illumination, etc. [13] However, the digital rendering engines have excelled in creating more realistic photo images much closer to the actual designs. Rendering is considered as the best artistic application in design presentations to show the form, depth, shape, activity, etc. more precisely. The quality of the rendering, i.e. resolution increases the configuration of the desktop or laptop required to proceed further. Many multinational architectural firms rely on separate servers for render farms to generate walkthroughs, animations, flythroughs, etc. at ease.

Recommended softwares: Revit, 3DsMax, Maya, Rhino, Grasshopper, Dynamo, V-ray, Zbrush, Vector Works, Modo, Solidworks, Alias, Unity, Mudbox, Blender, Arcon Evo, Data CAD, etc.

\subsection{Slide Shows (Digital Only)}

A Slideshow consists of a series of still images or video clippings with or without audio output, projected on a white screen in an appropriate sequence controlled manually by the operator. This process is used in any stream of education or research with their respective artistic value that may or may not include description, information, solutions, problems, comments, images $(2 \mathrm{D}$ or $3 \mathrm{D})$, etc. presented verbally to a set of audience. [14] Educational institutions use this as one of their teaching methods to show more updated knowledge effectively as this can be saved, re-read, preserved, edited, etc. Animation and other effects for slides 
or images with specific instructions is more reliable way of attracting and reducing the boredom of long teaching hours that helps in crafted designs and captivate the pupils.

Recommended softwares: Powerpoint, Indesign, Prezi, Captivate, Excel, Google Apps, Office, Blackboard, Quickbooks, Adobe Acrobat reader, Workflow Max, etc.

\subsection{Virtual Tours (Walk-Through, Fly-Through,}

\section{Etc.)}

They are composed of a systematic sequence of rendered still images taken at a walking pace while moving the camera in the digital software continuously from one point to another as per requirement so as to form photographicbased media i.e. animated video, in order to demonstrate the visual connectivity of spaces as well as understand the quality of designed spaces prior to construction. [15] It may also be included with other multimedia setups such as background sound, narrative description, music, subtitles, etc.

Recommended softwares: Revit, Maya, 3DsMax, Aftereffects, Adobe Flash, Premiere, Vimeo, iMovie, FinalCut Pro, Nuke, Motion, Trapcode, Avid, etc.

\subsection{Special Softwares (Urban Design,}

\section{Sustainability, Morphology, Simulations, Etc.) [16]}

Special softwares are designed that provide insight for high quality and intelligent structures with economical viability and reduced environmental impacts streamlining the specifications, visualization and simulation breaking down the barriers for execution of a more efficient project in place. [17]

Recommended softwares: Ecotect (Simulation), GIS (Urban Planning), Flexism (Simulation), Bentley AECOsim, Digital Project, Revit (Building Information Modeling), Maya (Realistic rendering), V-ray (rendering), City Engine (Urban Design), Diolkas (Roads or Terrain), Layour-iQ (Healthcare), MASTERSPEC (Libraries), PIMARC (Surveying), VisionREZ (Residences), Green Building Studio, Arch view, Arch info, etc.

\subsection{Websites or Personal Blogs Or Portfolios}

Architects are required to build design portfolios to draw client's attention or get employment by demonstrating their ideology, presentation techniques and digital knowledge base. [18] This helps in fetching better job prospects, creates an identity in the work atmosphere and a strong stand to compete in this industry. Handling all the manual sketches or drawings may not be comfortable on the long run. With the advent of software technology, creating a personal website with vector or raster graphics of academic or professional works, storing the relevant data in servers, online render farms, etc. might help in accessing the data whenever and wherever necessary.
Recommended softwares: Adobe Flash, Photoshop, Illustrator, Corel Draw, Bootstrap, Html, Dreamweaver, WordPress, Joomla, Javascript, CSS, WYSIWYG editing software, Google drive, cloud, etc.

\section{CONCLUSION}

Keeping abreast an era of centripetal architecture that was based on inspirations from nature and its forms, we now have moved into a period of emotional architecture that creates a balance between art, construction, technology, fabrication and sustainability within the building industry, thereby setting up a transformative stage for future architectural concepts in the years to come. [19] The immediate tool for manifesting an idea is "to sketch" on a piece of paper, board, sand, etc. that is being exercised on a silicon screen with the employment of several digital programs as until recently, and this might append the scope by adding more digital dimensions to the designed spaces in virtual reality, facilitating the designer to present tangible models with the possibility of experimenting with simulations, resulting in provision of emotional experience quotient to the client.

\section{REFERENCES}

[1]. Hogrefe, A. (2014). visualizing architecture. Retrieved September 28, 2015, from www.visualizingarchitecture.com: https://visualizingarchitecture.com/

[2]. Greynium Information Technologies Pvt. Ltd. (2015, July 07). What is Digital Architecture? Retrieved December 12, 2015, from http://www.careerindia.com/: http://www.careerindia.com/courses/uniquecourses/what-is-digital-architecture-015089.html

[3]. Snoonian, D. (May 2002). 'Digital architect. The case for a digital master builder. Architectural Record , 289290.

[4]. Steele, J. (2002). Architecture and Computers: Action and Reaction in the Digital Design Revolution. New York: Watson-Guptill Publications.

[5]. Leach, N. (2002). Designing for a Digital World (Architectural Design). London: Academy Press.

[6]. Stuck in Studio. (2011). ARCHITECTURAL SOFTWARE - WHAT ARE MY OPTIONS? Retrieved March 23, 2016, from www.stuckinstudio.com: http://stuckinstudio.com/resources/59-architecturalsoftware-what-are-my-options.html

[7]. Engeli, M. (2001). Bits and Spaces: Architecture and Computing for Physical, Virtual, Hybrid Realms, 33 Projects by Architecture and CAAD, ETH Zurich . Basel: Birkhauser Verlag AG.

[8]. Kilkelly, M. (2014, February 27). Which architectural software is right for me? Retrieved February 16, 2016, from www.archsmarter.com: http://archsmarter.com/which-architectural-software/

[9]. Oxman, R. (2005). The conceptual content of digital architecture. A content analysis in design . Arquitetura Revista . 
[10]. 2016 Autodesk Inc. (n.d.). Workflow for architectural design. Retrieved January 15, 2016, from http://www.autodesk.com/:

http://www.autodesk.com/industry/architectureengineering-construction/architecture-design

[11]. Capterra Inc. (n.d.). Top Architecture Software Products. Retrieved January 03, 2016, from www.capterra.com:

http://www.capterra.com/architecture-software/

[12]. Cook, J., Peter, W. H., \& Mathieu, L. (2011, May 02). Digitalarti Digital art \& innovation. Retrieved November 22, 2015, from http://media.digitalarti.com/: http://media.digitalarti.com/blog/digitalarti_mag/digital architecture

[13]. 2016 Act-3D B.V. (n.d.). 3D RENDERING SOFTWARE. Retrieved February 29, 2016, from www.lumion3d.com: rendering-software.html

[14]. Rahim, A. (2000). Contemporary Processes in Architecture. Academy Press.

[15]. Sandy. (2015, March 08). The 25 Best 3D Rendering Software. Retrieved February 14, 2016, from www.rockthe3d.com: http://www.rockthe3d.com/25best-3d-rendering-software/

[16]. CGARCHITECT DIGITAL MEDIA CORP. (2014). Visualization on Insider. Retrieved March 03, 2016, from http://www.cgarchitect.com/: http://www.cgarchitect.com/content/posts/legacy/Visua lizationInsider/Week23/VI_Week23.pdf

[17]. lynda.com a linkedin company. (n.d.). all subjects. Retrieved February 12, 2016, from www.lynda.com: http://www.lynda.com/subject/all

[18]. VagueWare.com is powered by WordPress \& +62 . (2013, February 05). Top 10 Architectural Design Software for Budding Architects. Retrieved January 05, 2016, from www.vagueware.com: http://www.vagueware.com/top-10-architecturaldesign-software-for-budding-architects/

[19]. Szalapaj, P. (2004). Contemporary Architecture and the Digital Design Process. Architectural Press.

\section{BIOGRAPHIES}

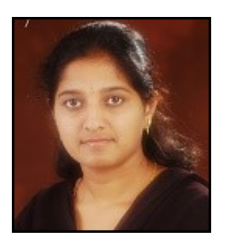

Ar. Suryakala Nannapaneni, she is working as Asst. Professor in School of Architecture, GITAM UniversityVisakhapatnam; previously she has done her Masters in Architecture at Savannah College of Art and Design, Georgia-United States of America. Her research focuses on contemporary and sustainable aspects of Architecture and Urban Design. Ph. No. +91 9052678363 (or) Email. architectkala@gmail.com

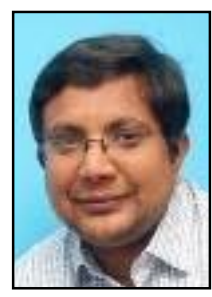

Ar. Ravindra Patnayaka, he is working as Asst. Professor in School of Architecture, GITAM University-Visakhapatnam; previously he has done his Master in Planning at JNAFAU, Hyderabad. His research focuses on integrating Urban Design and Architectural elements through empirical and logical solutions.

Ph. No. +91 $8008413476 \quad$ (or) Email.

